\title{
Effect of Extracorporeal Membrane Oxygenation on Body Water Content and Distribution of Baboon Neonates ${ }^{1}$
}

\author{
YVES W. BRANS, J. DEVN CORNISH, THOMAS J. KUEHL, ELISABETH B. DUTTON, \\ DONNA S. ANDREW, AND ELIZABETH M. MENCHACA
}

\author{
Perinatal Research Laboratory, Departments of Pediatrics and Obstetrics and Gynecology, The University of \\ Texas Health Science Center at San Antonio [Y.W.B., E.B.D., D.S.A., E.M.M.]; Perinatal Biology Program, \\ Southwest Foundation for Biomedical Research [Y.W.B., T.J.K.J; and Division of Neonatology, Department of \\ Pediatrics, Wilford Hall USAF Medical Center [J.D.C.], San Antonio, Texas
}

\begin{abstract}
Water contents of the various body compartments were estimated before and after a $7-$ to 10 -h period of extracorporeal membrane oxygenation in five healthy baboon neonates. Total body water, extracellular water, and plasma volume were estimated simultaneously by antipyrine, bromide, and T-1824 dilution. Volumes of intracellular water, interstitial water, and blood and red cells were calculated from the experimental estimates. Mean preextracorporeal membrane oxygenation estimates of body water volume were in agreement with those previously reported in baboon neonates. During extracorporeal membrane oxygenation, no statistically significant changes occurred in the water content of the various body compartments. This absence of changes was contrasted to the changes demonstrated in human infants and adults undergoing intracardiac surgery with extracorporeal oxygenation and hypothermia and various hypotheses were put forward to explain the different changes observed. (Pediatr Res 20: 381-384, 1986)
\end{abstract}

\section{Abbreviations}

ECMO, extracorporeal membrane oxygenation CBS, corrected bromide space

Body composition of adult patients has been shown to be acutely altered by open heart surgery with hypothermia and extracorporeal circulation $(1,2)$. Total body water and intracellular water remained stable, but extracellular water increased, particularly in the interstitial compartment. An earlier study suggested that similar changes occurred in young children and infants (less than 28 months of age) (3). It was not clear, however, whether the observed changes were related to extracorporeal oxygenation (the procedure itself or the type of oxygenation), to hypothermia, or to a combination of both factors. This study was designed to identify changes in body water content and distribution resulting from extracorporeal membrane oxygenation without hypothermia in healthy baboon neonates.

Received September 9, 1985; accepted December 17, 1985.

Supported in part by a grant from the James R. Dougherty, Jr. Foundation, Beeville, TX and by a research grant from the United States Air Force.

${ }^{1}$ The opinions expressed in this manuscript are those of the authors and not necessarily those of the United States Air Force or the Department of Defense.

\section{METHODS}

Five healthy baboon (Papio cynocephalus) neonates (two male and three female) were studied. Postnatal ages at the time of study ranged from 17 to 28 days. Body weights, measured to the nearest gram, ranged from 820 to $1478 \mathrm{~g}$. Each animal was anesthetized with $10 \mathrm{mg} / \mathrm{kg}$ ketamine hydrochloride and 0.05 $\mathrm{mg} / \mathrm{kg}$ diazepam. These doses were repeated as needed for sedation until muscle relaxants were instituted. Thereafter, both drugs were administered every 20 min for three doses, every 30 min for two doses and then hourly. A neonatal monitor was used to measure rectal temperature, heart rate, and respiratory rate. Each animal was intubated using a $3.0-\mathrm{mm}$ internal diameter endotracheal tube which fit snugly through the vocal cords. Pancuronium bromide $0.2 \mathrm{mg} / \mathrm{kg}$ was administered and the ventilator was adjusted as required. The right femoral artery was catheterized using a $3.5 \mathrm{~F}$ umbilical artery catheter. This line was used to monitor the animal's blood pressure and arterial blood gasses. The left femoral artery was also catheterized with the largest allowable catheter ( 5 or $6 \mathrm{~F}$ ). This catheter was used to return oxygenated blood to the distal aorta. A Bourns BP 200 ventilator was adjusted to provide an arterial $\mathrm{pCO}_{2}$ of 35 to 45 Torr and an arterial $\mathrm{pO}_{2}$ greater than or equal to 55 Torr.

Through an incision medial to the belly of the right sternocleidomastoid muscle, the right internal jugular vein and common carotid artery were identified. Both vessels were isolated and prepared for cannulation. A 3.5 or $5 \mathrm{~F}$ umbilical artery catheter was passed distally up the internal jugular vein to the base of the skull and the vein was ligated proximally. Through the carotid artery, the largest allowable catheter $(5$ or $6 \mathrm{~F}$ ) was passed to the level of the aortic arch. This catheter was used to return oxygenated blood to the proximal aorta. A midline sternotomy was performed and the pericardium was reflected and secured to the sternal edges. The ductus arteriosus was identified and ligated, and umbilical tapes were passed around the root of the aorta and the pulmonary artery and out through a cut segment of red rubber catheter to serve as Romel snares. A 14 F venous cannula was introduced into the right atrium through an incision in the right atrial appendage, and the cannula was secured in place. The positions of all catheters and of the endotracheal tube were verified radiographically.

The ECMO circuit was assembled and primed as described previously by Bartlett (4). Blood samples $(125 \mathrm{ml})$ were collected from each of four healthy adult baboons and pooled 24 to $72 \mathrm{~h}$ prior to each experiment. The blood was centrifuged to separate the plasma from the red cells within a few hours of drawing. The red cells were then stored at $4^{\circ} \mathrm{C}$ until the pump was primed just 
prior to each perfusion run. The blood in the circuit was circulated using a Sarns $\mathrm{S}_{10} \mathrm{~K}_{11}$ roller pump (Sarns, Inc., Ann Arbor, MI). A Gaymar T/Pump (Model TP-200, Gaymar, Orchard Pk, NY) was used to heat and circulate water through a SciMed model P-7-14 Omnitherm (Pediatric) Heat Exchanger (SciMed Life Systems, Inc., Minneapolis, MN). The servo control device ("bladder box") used to match the pump output rate to the venous gravity drainage rate was manufactured locally using plans provided by Dr. Robert H. Bartlett. A 0.4 or $0.8 \mathrm{~m}^{2}$ SciMed/Kolobow membrane lung was used. Because of the small size of the animals and the inherent capacitance of the circuit, volume was added to the circuit prior to beginning bypass to bring the circuit pressure up to $300 \mathrm{~mm} \mathrm{Hg}$. This effectively prevented episodes of hypotension due to volume loss from the animal into the circuit on initiating bypass. The blood gases and clotting times of the blood in the ECMO circuit were adjusted by regulating the rate of carbon dioxide and oxygen flow into the membrane, by adding sodium bicarbonate to the blood, and by adding heparin to the blood in the circuit using a slow heparin infusion, respectively, as required. The fractional concentrations of oxygen, carbon dioxide, and nitrogen entering the membrane oxygenator were monitored throughout the experiment using a Perkin-Elmer Model 1100 Medical Gas Analyzer (Perkin-Elmer Corp., Medical Instruments Div., Pomona, CA).

The ECMO part of the study was performed in two phases (Cornish JD, Gertsmann DR, Null DM Jr, Smith MD, Kuehl TJ, unpublished data). The first phase of the experiment was designed to assess the effects of decreasing the perfusion flow rate using fully oxygenated blood. It began when the connections to the venous and arterial catheters were made and the bypass flow was diverted to the animal. At this time a second dose of pancuronium bromide $(0.2 \mathrm{mg} / \mathrm{kg})$ was administered, the endotracheal tube was clamped, the ventilator was turned off, and the aorta and pulmonary artery were occluded using the snares which had been placed previously. Additional blood, plasma, and/or saline, depending on hematocrit and product availability, were added to the pump circuit as required to bring the perfusion flow rate to $200 \mathrm{ml} / \mathrm{kg} / \mathrm{min}$.

When this flow rate was achieved, the baseline period was begun. This was a 2-h segment designed to demonstrate the stability of the animal's oxygen consumption. During the baseline period, the flow rate was kept constant at $200 \mathrm{ml} / \mathrm{kg} / \mathrm{min}$. At the end of the baseline period, the pump flow rate was decreased every $30 \mathrm{~min}$ going from 200 to 150 to 100 to 75 to $50 \mathrm{ml} / \mathrm{kg} / \mathrm{min}$. After $30 \mathrm{~min}$ at each flow rate, and before switching to the next rate, blood was sampled at the pump arterial and venous sites, the cerebral venous sites, and the femoral artery site for blood gas measurements and other chemistries. Heart rate (where applicable), blood pressure, body temperature, and pump flow rate were monitored continuously and were recorded at 15 - to 30 -min intervals. Urine output was collected and recorded.

At the end of the $50 \mathrm{ml} / \mathrm{kg} / \mathrm{min}$ flow period, the pump rate was returned to a flow of $200 \mathrm{ml} / \mathrm{kg} / \mathrm{min}$, still with maximal hemoglobin oxygen saturation. This marked the beginning of the second or saturation phase of the study. Throughout this phase, animals were perfused at $200 \mathrm{ml} / \mathrm{kg} / \mathrm{min}$. However, the fractional "inspired" oxygen concentration delivered to the membrane $\left(\mathrm{FiO}_{2}\right)$ was reduced every $30 \mathrm{~min}$ from 1.0 to 0.26 to 0.19 to 0.6 to 0.14 , corresponding roughly to decreases in baboon hemoglobin saturation from 100 to 75 to 40 to 30 to $25 \%$. This was done by attaching nitrogen and oxygen lines to an oxygen blender. The output from the blender was further mixed through a Y connector with carbon dioxide from a separate source. The fractional content of each gas being delivered to the membrane was measured using a mass spectrometer. Serum chemistry was determined again at the beginning of the saturation phase. Vital signs and hematologic parameters were sampled at 15-, 30-, and 60-min intervals as in the first phase of the study.

Water contents of the various body compartments were esti- mated before connecting the baby to the ECMO circuit. Antipyrine space (total body water), corrected bromide space (extracellular water) and plasma volume (10-min albumin space with $\mathrm{T}-1824$ on the albumin tag) were estimated simultaneously following injection of $4 \mathrm{ml} / \mathrm{kg}$ of a solution containing $0.5 \mathrm{~g} / \mathrm{dl}$ of antipyrine, $2.5 \mathrm{~g} / \mathrm{dl}$ of sodium bromide, and $2.5 \mathrm{~g} / \mathrm{dl}$ of T-1824 dissolved in $0.9 \mathrm{~g} / \mathrm{dl}$ sodium chloride. The technique has been previously described in detail (5), but two corrections should be made to this description: a factor of 0.977 was used in the formula for calculation of antipyrine and corrected bromide spaces in order to correct for the proportion of water in plasma (6), and the formula for CBS should read

$\mathrm{CBS}=\frac{\text { amount } \text { of bromide injected }}{1 \mathrm{~h} \text { plasma bromide concentration }}$

$\times 0.90 \times 0.95 \times 0.977$

Intracellular water content, interstitial water content, blood volume, and red cell volume were calculated. The volume of intracellular water was assumed to be the difference between antipyrine space and corrected bromide space. The volume of interstitial water was assumed to be the difference between corrected bromide space and plasma volume. Blood volume was calculated from plasma volume and hematocrit. Red cell volume was assumed to be the difference between blood and plasma volumes. As soon as the ECMO circuit was primed, its plasma volume was estimated by T-1824 dilution; its blood volume was calculated from plasma volume and the hematocrit of the blood in the circuit.

At the completion of the study, the estimates of body water content and distribution of the baboon plus the ECMO circuit were repeated, as no attempt was made to wean the baby off ECMO. The circuit was then disconnected and the volumes of plasma and blood in the circuit were measured. The estimates of body water content and distribution labeled "post-ECMO" were calculated by subtracting the volumes of fluid remaining in the circuit from those estimated in the baboon plus the circuit.

All estimates of body water content were expressed in $\mathrm{ml} / \mathrm{kg}$ of body weight. Pre- and post-ECMO estimates were compared by means of Student's paired $t$ test.

\section{RESULTS}

Pre- and post-ECMO estimates of water contents of the various body compartments and of the pump circuit are summarized in Table 1. The mean differences between post- and pre-ECMO estimates are displayed in Figure 1. An average of $8 \mathrm{~h}$ of ECMO did not appear to affect any of the water compartments of the body.

Similar mean pre- and post-ECMO estimates were observed for the antipyrine space [ $843 \pm$ (SE) 37.4 versus $787 \pm 80.5 \mathrm{ml} /$ $\mathrm{kg}]$, CBS (361 \pm 47.6 versus $409 \pm 17.6 \mathrm{ml} / \mathrm{kg})$, and intracellular water $(482 \pm 64.2$ versus $379 \pm 57.0 \mathrm{ml} / \mathrm{kg})$. The mean difference between post- and pre-ECMO values for antipyrine space $(56 \pm$

Table 1. Pre-and post-ECMO estimates of body water content and distribution (mean $\pm S E$ in $\mathrm{ml} / \mathrm{kg}$ )

\begin{tabular}{lcc}
\hline \multicolumn{1}{c}{ Compartment } & Pre-ECMO & Post-ECMO \\
\hline Antipyrine space & $843 \pm 37.4$ & $787 \pm 80.5$ \\
CBS & $361 \pm 47.6$ & $409 \pm 47.6$ \\
Intracellular water & $482 \pm 64.2$ & $379 \pm 57.0$ \\
Interstitial water & $308 \pm 45.0$ & $350 \pm 36.7$ \\
Plasma volume & $53 \pm 8.2$ & $58 \pm 19.2$ \\
Blood volume & $84 \pm 12.8$ & $95 \pm 18.9$ \\
Red cell volume & $31 \pm 4.8$ & $36 \pm 11.2$ \\
Pump circuit volume & $437 \pm 45.4^{*}$ & $387 \pm 30.4^{*}$ \\
Pump circuit + blood volume & $531 \pm 52.1$ & $496 \pm 25.9$ \\
\hline
\end{tabular}

${ }^{*} p=0.038$. 


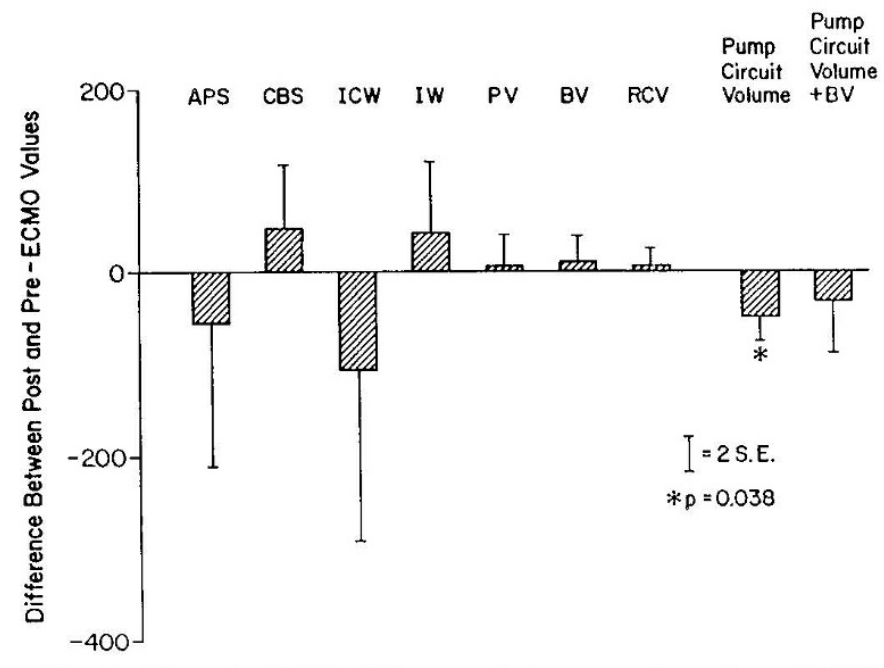

Fig. 1. Mean ( $\pm 2 \mathrm{SE}$ ) differences between post- and pre-ECMO estimates of antipyrine space $(A P S), \mathrm{CBS}$, intracellular water $(I C W)$, interstitial water $(I W)$, plasma volume $(P V)$, blood volume $(B V)$, red cell volume $(R C V)$, pump circuit volume, and pump circuit plus blood volume. All values are expressed in $\mathrm{ml} / \mathrm{kg}$ of body weight.

$77.2 \mathrm{ml} / \mathrm{kg})$, CBS $(-48 \pm 34.6 \mathrm{ml} / \mathrm{kg})$, and intracellular water $(103 \pm 91.8 \mathrm{ml} / \mathrm{kg})$ were not significantly different from zero.

Similarly, mean pre- and post-ECMO blood volumes $(53 \pm$ 8.2 versus $58 \pm 19.2 \mathrm{ml} / \mathrm{kg})$, blood volumes $(84 \pm 12.8$ versus $95 \pm 18.9 \mathrm{ml} / \mathrm{kg})$, and red cell volumes $(31 \pm 4.8$ versus $36 \pm$ $11.2 \mathrm{ml} / \mathrm{kg}$ ) were similar. The mean differences between postand pre-ECMO volume for plasma volumes $(-5 \pm 17.5 \mathrm{ml} / \mathrm{kg})$ blood volumes $(-10 \pm 14.4 \mathrm{ml} / \mathrm{kg})$, and red cell volumes $(-5 \pm$ $9.7 \mathrm{ml} / \mathrm{kg}$ ) were not significantly different from zero.

Interstitial water estimates averaged $308 \pm 45.0 \mathrm{ml} / \mathrm{kg}$ before and $350 \pm 36.7 \mathrm{ml} / \mathrm{kg}$ after ECMO. The mean difference between pre- and post-ECMO value $(-43 \pm 38.5 \mathrm{ml} / \mathrm{kg})$ was not significantly different from zero.

The estimated volume of blood in the pump circuit decreased significantly from a mean of $437 \pm 45.4 \mathrm{ml} / \mathrm{kg}$ to a mean of 387 $\pm 30.4 \mathrm{ml} / \mathrm{kg}$. The mean difference between post- and pre-ECMO estimates $(-50 \pm 14.0 \mathrm{ml} / \mathrm{kg})$ was significantly different from zero $(p=0.038)$. The mean decreases in total volumes of blood in the pump circuit and the neonate were similar before and after ECMO $(531 \pm 52.1$ versus $496 \pm 25.9 \mathrm{ml} / \mathrm{kg})$.

\section{DISCUSSION}

Acute alterations of body water content and distribution have been reported in adults subjected to intracardiac surgery with hypothermia and extracorporeal oxygenation. Although most patients showed an increase in total body water, mean total body water contents were not significantly greater after surgery than before (2). Intracellular water content was unaffected. Extracellular water content, on the other hand, increased by a mean of 7 to $19 \%(1,2)$. These changes did not affect the extracellular compartment homogeneously: interstitial (extravascular) water increased by a mean of $12.5 \%$ whereas plasma (intravascular) volume remained unchanged (2). Our earlier studies suggested that infants and young children, aged 28 months or less, behaved similarly to adults in the course of technically similar procedures (3). Total body water increased in most infants during surgery, but not significantly so, and intracellular water content remained stable. Although the mean increase was not statistically significant, extracellular water volume did increase slightly in most patients. As in adults, extracellular water expansion was limited to the interstitial space where it increased by an average of $30 \%$ over preoperative levels and the intravascular volume was not affected. The cause for these changes was not clear. They could be related to the overall trauma of surgery and anesthesia, to extracorporeal oxygenation, to hypothermia or to a combination of these factors.

The present study afforded an opportunity to study the effect of extracorporeal oxygenation independently of the other factors. We have previously shown that body water content and distribution in normally grown term baboon neonates were similar to those of human neonates during the first 24 postnatal h $(6,7)$. We have also shown that the mean water content of the various compartments of the body, with the exception of red cell volume, was similar in normally grown baboon neonates studied on days 1 or 29 after birth (8). Pre-ECMO values in this study are in agreement with those reported earlier. During ECMO, no statistically significant changes occurred in the water content of the various body compartments, nor was there any trend toward changes. The decrease in the volume of blood within the pump circuit may be explained by underestimation of blood losses during the experimental period and therefore insufficient replacement by transfusions, by some shift of blood from the circuit to the body at the time of disconnection of the ECMO circuit (due to clamping the venous drainage line before the arterial return line), and by increased insensible losses from the membrane lung. These losses alone have been estimated at 150 to $300 \mathrm{ml} /$ day at the gas flow rates used in this study (Bartlett $\mathrm{RH}$, personal communication).

The absence of changes observed in baboons is strikingly different from the changes observed in humans. Several explanations may be suggested. First, it may be argued that baboons are different from humans in their metabolic response to ECMO. Although available data do not rule out this possibility, it is not likely in view of a large body of literature showing considerable metabolic similarities between baboons and humans (including studies in the perinatal period) and few dissimilarities. Second, in this investigation we studied healthy baboons subjected to a short, acute asphyxic insult, whereas human studies involved patients with a history of chronic congenital heart disease. In our model, pump flow rates were sequentially decreased from 200 to $50 \mathrm{ml} / \mathrm{kg} / \mathrm{min}$ in 25 - to $50-\mathrm{ml}$ increments each $1 / 2 \mathrm{~h}$ for the first $4 \mathrm{~h}$ of the experiment, while hemoglobin saturation was maximized. During the final $2.5 \mathrm{~h}$ of the experiment, flow was maintained at a supra-normal rate of $200 \mathrm{ml} / \mathrm{kg} / \mathrm{min}$ while hemoglobin saturation was decreased incrementally every 30 min. Evidence derived from monitoring blood $\mathrm{pH}$ and bicarbonate, serum lactate levels, and oxygen delivery and consumption patterns shows that compromising levels of oxygen delivery were reached only in the last $30 \mathrm{~min}$ of the first phase and the last 60 min of the second phase of the experiment (Cornisin JD, Gertsmann DR, Null D Jr, Smith MD, Kuehl TJ, unpublished data). Thus any hypoxic insult was acutely induced and of relatively short duration when compared with chronically ill humans with heart disease. In the human experience, factors such as severity of heart failure and reordering of hemodynamic equilibrium after correction of major cardiac defects have probably played a role. Third, there were major differences in the equipment used for extracorporeal oxygenation. In human studies, either a disk oxygenator $(1,2)$ or a bubble oxygenator $(2,3)$ was used, and these instruments required volumes of blood and crystalloid solutions to prime the circuit that were many times larger than the blood volume of the infants. In this study, a membrane oxygenator designed for use in neonates with a mean total circuit volume of $482 \mathrm{ml}$ was utilized. Indeed, alterations in body water volume observed in adults and infants have been blamed on retention by the body of some of the priming fluids $(1,3)$. Proposed mechanisms for such fluid retention include a decrease in plasma colloidal pressures by the dilute perfusion solution and an increase in capillary permeability to albumin secondary to anoxia of capillary endothelia during the procedure (2). A tendency to damage formed blood elements $(9,10)$ and to release intracellular lysosomal hydrolases (11) are among the other differences between bubble and membrane oxygenation. Fourth, the duration of ECMO was much longer in the baboon 
study. In human studies, estimates were obtained 1 day before and 1 day after the procedure. During the postoperative day, a number of changes unrelated to ECMO may have occurred. A strength of our investigation was that water content and distribution were estimated immediately before and after ECMO procedure. The true effect of extracorporeal circulation on interstitial fluid balances was likely to be represented more accurately and confounding variables minimized. Finally, the differences between baboons and humans may be related to the absence of hypothermia in the baboon studies. This would suggest that hypothermia rather than extracorporeal oxygenation may have been responsible for the changes observed in humans.

In view of the increasing use of ECMO in the treatment of neonates with severe but transient pulmonary injury, the metabolic effects of ECMO deserve to be investigated carefully. The current study, which shows no significant changes in the water content of the various body compartments during ECMO, suggests that the extracorporeal circulation techniques currently in use in neonates may pose fewer risks from body fluid shifts than might have been expected on the basis of previous reports.

\section{REFERENCES}

1. Breckenridge NM, Digerness SB, Kirklin JW 1970 Increased extracellular fluid after open intracardiac operation. Surg Gynecol Obstet 131:53-56
2. Pacifico AD, Digerness SB, Kirklin JW 1970 Acute alteration of body composition after open intracardiac operations. Circulation 41:331-341

3. Brans YW, Dweck HS, Harris HB, Parr GVS, Bailey PE, Kirklin JW, Cassady G 1981 Effect of open-heart surgery on the body composition of infants and young children. Pediatr Res 15:1024-1028

4. Bartlett RH 1984 ECMO-Technical Specialist Manuals. University of Michigan, Ann Arbor

5. Thornton CJ, Shannon DL, Hunter MA, Ramamurthy RS, Brans YW 1983 Body water estimates in neonatal polycythemia. J Pediatr 102:113-117

6. Brans YW, Kuehl TJ, Hayashi RH, Shannon DL, Reyes P 1983 Body water estimates in normally-grown baboon neonates. Am J Primatol 5:69-75

7. Brans YW 1985 Error in calculation of corrected bromide space. Am J Primatol 9:231-233

8. Brans YW, Dutton EB, Shannon DL, Menchaca EM, Kuehl TJ Estimate of body water content in normally-grown baboons during the first postnatal months. J Med Primatol (in press)

9. Peterson KA, Dewanjee MK, Kaye MP 1982 Fate of indium-111-labeled platelets during cardiopulmonary bypass performed with membrane and bubble oxygenator. J Thorac Cardiovasc Surg 84:39-47

10. Boers M, van der Dungen JJAM, Karliczek GF, Brenken U, Homan vander Heide JN, Wilderuur CRH 1983 Two membrane oxygenators and a bubbler: a clinical comparison. Ann Thorac Surg 35:455-462

11. Addonizio VP Jr, Strauss JF III, Chang LF, Fisher CA, Colman RW, Edmunds LH Jr 1982 Release of lysosomal hydrolase during simulated extracorporeal circulation. J Thorac Cardiovasc Surg 84:28-34 